\title{
Erratum to: Why We Live in Hierarchies?
}

\section{Erratum to:}

\section{A. Zafeiris and T. Vicsek, Why We Live in Hierarchies? SpringerBriefs in Complexity, https://doi.org/10.1007/978-3-319-70483-8}

The original version of the book was inadvertently published with the following errors, which have been now corrected:

Affiliation of "Anna Zafeiris", "Biological Physics Department, ELTE, Budapest, Hungary" has been changed as "Department of Biological Physics, Eötvös Loránd University, Budapest, Hungary" in Frontmatter, which is a belated correction.

In chapter 3, the author name "Anna Zafeiris-Lazar" has been changed as "Anna Zafeiris".

\footnotetext{
The updated online version of the book can be found at https://doi.org/10.1007/978-3-319-70483-8

https://doi.org/10.1007/978-3-319-70483-8_3

(C) The Author(s) 2018
} 